\title{
Interactive comment on "Rayleigh wind retrieval for the ALADIN airborne demonstrator of the Aeolus mission using simulated response calibration" by Xiaochun Zhai et al.
}

Xiaochun Zhai et al.

zhaixiaochun@163.com

Received and published: 27 November 2019

The comment was uploaded in the form of a supplement:

https://www.atmos-meas-tech-discuss.net/amt-2019-274/amt-2019-274-AC3-

supplement.pdf

Interactive comment on Atmos. Meas. Tech. Discuss., doi:10.5194/amt-2019-274, 2019. 